Article

\title{
The Practice of Civic Tech: Tensions in the Adoption and Use of New Technologies in Community Based Organizations
}

\author{
Eric Gordon ${ }^{1, *}$ and Rogelio Alejandro Lopez ${ }^{2}$ \\ ${ }^{1}$ Engagement Lab, Emerson College, Boston, MA 02116, USA; E-Mail: eric_gordon@emerson.edu \\ ${ }^{2}$ Annenberg School for Communication and Journalism, University of Southern California, Los Angeles, CA 90089, USA; \\ E-mail: rogeliol@usc.edu
}

* Corresponding author

Submitted: 5 April 2019 | Accepted: 10 July 2019 | Published: 6 August 2019

\begin{abstract}
This article reports on a qualitative study of community based organizations' (CBOs) adoption of information communication technologies (ICT). As ICTs in the civic sector, otherwise known as civic tech, get adopted with greater regularity in large and small organizations, there is need to understand how these technologies shape and challenge the nature of civic work. Based on a nine-month ethnographic study of one organization in Boston and additional interviews with fourteen other organizations throughout the United States, the study addresses a guiding research question: how do CBOs reconcile the changing (increasingly mediated) nature of civic work as ICTs, and their effective adoption and use for civic purposes, increasingly represent forward-thinking, progress, and innovation in the civic sector?-of civic tech as a measure of "keeping up with the times." From a sense of top-down pressures to innovate in a fast-moving civic sector, to changing bottom-up media practices among community constituents, our findings identify four tensions in the daily practice of civic tech, including: 1) function vs. representation, 2) amplification vs. transformation, 3) grassroots vs. grasstops, and 4) youth vs. adults. These four tensions, derived from a grounded theory approach, provide a conceptual picture of a civic tech landscape that is much more complicated than a suite of tools to help organizations become more efficient. The article concludes with recommendations for practitioners and researchers.
\end{abstract}

\section{Keywords}

civic sector; civic technology; community based organizations; community organizing; information communication technologies; innovation; youth media

\section{Issue}

This article is part of the issue "Civic Organizations and Digital Technologies in an Age of Distrust", edited by Eric Gordon (Emerson College, USA).

(C) 2019 by the authors; licensee Cogitatio (Lisbon, Portugal). This article is licensed under a Creative Commons Attribution 4.0 International License (CC BY).

\section{Introduction}

Mobile websites for government services, social media tools to connect local neighborhoods, transportation apps to track buses and trains: these are examples of what are often called "civic technologies," or technological tools that promote, facilitate, or coordinate civic actions (Open Plans, 2012; Gordon \& Mihailidis, 2016). The space of civic technology (civic tech) has grown significantly since 2012, propelled partly by the non-profit
Code for America (Schrock, 2018), as well as small startup companies embracing the term, and tech giants such as Microsoft and Google developing civic tech divisions. The context to this shift in professional practice is a growing data infrastructure that has prompted changes in government decision making (Heuer, Penrod, \& Kattan, 2007; O'Brien, 2018) and approach to service delivery (Noveck, 2008). The enthusiasm around open data (Goldstein, 2013) and civic tech has motivated scores of municipal governments to form "innovation offices" 
charged with inventing and integrating technologies that enable and streamline the work of government (Bowles \& Giles, 2012; Jacob, 2015). These inchoate offices are focused on inventing new tools or creatively adapting existing ones (i.e., Facebook or Twitter), and generally bridging the organizational cultures of government bureaucracy with tech-sector entrepreneurialism (Poje, 2011; Wells, 2015). The technology evangelist Tim O'Reilly's concept of "government as platform" has guided the work of Code for America in particular, and advocates for government to be a more nimble staging area for experimentation and innovation by serving as a platform for services (internal or third-party) and not simply a provider of services (O'Reilly, 2010). Municipal governments are attempting to overhaul procurement procedures in order to more effectively partner with companies and universities. Part of the promise of civic tech has been the potential to circumvent inefficient bureaucracies by facilitating a more participatory and open environment between citizens and civic organizationsgovernment or otherwise.

As a result of, or at least in parallel to, this momentum in government, civic tech is gaining influence in the civil society sector as well. Among non-profits and social enterprises, the desire to use technology to connect with and empower constituent participation is increasing. Civic organizations, from small community-oriented non-profits to advocacy organizations, are attempting to bridge the gap between decision-making and civic participation through the development or appropriation of information and communication technologies (ICTs). ${ }^{1}$ For many civic organizations, ICTs represent an opportunity to re-conceptualize longstanding methods to increase civic engagement and political participation, such as grassroots community organizing aimed at engaging people historically excluded by electoral and deliberative politics (Nabatchi \& Leighninger, 2015). Whether it is connecting to constituents, streamlining the use of data, changing organizational culture, or engaging different or younger people, the use of ICTs for the purpose of promoting, facilitating or coordinating civic actions is perceived as an increasingly important part of organizational missions and cultures (Gordon \& Mugar, 2018; Patel, Sotsky, Gourley, \& Houghton, 2013; Place Matters \& Ford Foundation, 2014).

While some attention is paid to these shifting cultures, the academic study of civic tech is still very much concerned with evaluating the effectiveness of individual tools (Simon, Bass, Boelman, \& Mulgan, 2017; Schrock, 2018). And while this is important work, it leaves out potential to examine social and cultural factors that influence the adoption of ICTs by civic organizations. There is a need to understand how technological innovations generate interest, get deployed, get used in practice
(Couldry, 2012) both intra- and extra- organizationally, and how they are sustained over time within the social, civic and political realities of their use. In the current study, we investigate how ICTs are transforming civic practitioners' understanding of their work, specifically within community based organizations (CBOs). This goal is guided by two central research questions: 1) As ICTs - and their promise to democratize and facilitate participation-proliferate in the civic sector, how do CBOs reconcile their need to innovate, modernize, and stay on-the-cutting-edge technologically while also securing their continued role as brokers between (and amongst) citizen constituents and local governments? And 2) How do CBOs remain relevant at a time when people are more and more able to self-organize through digital networks, or as Clay Shirky (2008) asserts, organize without organizations? If ICTs allow individuals to selforganize, advocate, and petition local authorities, processes which $\mathrm{CBO}$ s themselves have long facilitated on behalf of communities, then what is the role of the organization and how do they build and sustain relationships with their constituents? In an almost existential crisis, CBOs must simultaneously adopt ICTs to survive in a competitive civic sector to showcase relevance (at least for funding) while also retaining their grassroots identities as the champions of communities at large.

We locate the practice of civic tech as a kind of institutional entrepreneurship, which Maguire, Hardy, and Lawrence (2004) define as "activities of actors who have an interest in particular institutional arrangements and who leverage resources to create new institutions or to transform existing ones" (p. 657). The lens of entrepreneurship over organizational change allows for the consideration of greater agency than does the mainstream of organizational studies (Garud, Hardy, \& Maguire, 2007). The current research looks at the specific tensions that arise between individual actors (and the agency they bring to public work) and the institutional logics that guide the organizations at which they work in the context of technology adoption and adaptation.

Within CBOs specifically, we seek to understand where the tensions exist between adoption and use, and how practitioners are struggling with contradictions that technological mediation inserts into "public work." Harry Boyte (2019) defines public work as "nonviolent collaborative work across differences filled with public purpose and impact." This study focuses on the tensions that emerge as public work is mediated by civic organizations. The primary site of the research is the Dudley Street Neighborhood Initiative (DSNI) in Boston, MA. Founded in 1984 by residents of the neighborhood, it has grown substantially and obtained significant influence in the Boston area. It is the first and only organization in Boston

\footnotetext{
${ }^{1}$ While the term ICT captures most of the tools and processes we are referring to, there are some (non-digital) technologies that are also referred to as civic tech (i.e., community white boards, analog games, etc.). We will use the term ICT to encompass all information and communication technologies; but in some cases, specifically when people are responding to a broader context, we will use the term "technologies" to refer to the general space inclusive of ICTs, but that extends to other, potentially non-digital and non-networked tools.
} 
to gain the power of eminent domain by the Boston Redevelopment Authority (Medoff, 1999). We look at how DSNI has incorporated new technologies into its work. This includes the staff meetings where new digital tools get proposed, the challenges of interns running an organization's website or an outside developer introducing new tech that sits outside of the normal ways of doing things, and existing engagement methods like grassroots community organizing. Through our interviews and observations, we uncover the everyday moments where new technologies and new tools push up against practitioners' perceptions of doing good public work.

Bruno Latour's (1990) Actor Network Theory (ANT) provides some insight into this phenomenon. The tensions that emerge within organizations as new technologies are introduced has to do with how humans delegate tasks to non-humans, such as using Facebook to organize interest groups or using municipal reporting applications to take in complaints. Each of these delegated tasks brings up some anxiety or tension not only between human and non-human actors, but also between human organizations and automated digital networks. For example, once people adopt a tool, to what extent do they give that tool agency to do public work? ANT provides a mechanism to consider agency in organizations as belonging not only to human actors. Such a theoretical framework allows for a deeper understanding of tech tools in the life of an organization. But our central concern is not the mapping of actors in a network, but rather an understanding of the tensions that emerge when human actors are presented with the opportunity to delegate their public work to non-human agents.

We identify four primary tensions civic organizations experience as they delegate to non-human actors. Each of the tensions is not a silo, but an overlapping set of concerns and anxieties that run through the adoption and use of ICTs. Tensions should not be considered binaries; instead, they represent a range of emotions and challenges experienced by practitioners. They include 1) Function vs. representation, 2) Amplification vs. transformation, 3) Grassroots vs. grasstops, and 4) Youth vs. adults. These tensions are described in rich detail in the discussion section, and their implications for practitioners and researchers are explained in the conclusion.

\section{Methods}

We use a mixed methods approach. Data collection includes participant observation (over 50 pages of handwritten notes) and semi-structured interviews (32), taking place over nine months between September 2013 and June 2014. The ethnographic portion of this study pertains to the DSNI in the Roxbury neighborhood of Boston, MA, where a researcher was embedded as a par- ticipant observer. This researcher worked twenty hours a week within the organization, helping with the implementation of new tools and observing meetings and organizational structures. Additionally, the researcher coordinated with an external technology team that helped to design and implement new civic tech tools within the organization, including an online deliberation platform, informational touch screens in storefront windows and workshops on videography for youth. Journal-style notes were collected on a daily basis, with an emphasis on providing a thorough and richly detailed account of the organization's culture and day-to-day activities-especially as pertaining to the use of communication and media. 14 members of the organization's staff were interviewed at least once, and hours of observations were recorded. The 18 interviews at DSNI were semi-structured and were typically about an hour in length. All interviews from this organization are represented by the prefix DSNI in the citation, followed by a number (1-14). Follow-up interviews are represented by the number 2 following a dash (i.e., DSNI-2). The interviews represent all levels of the organization, from executive directors, to communication specialists, to community organizers, in addition to various degrees of experience within the organization across gender, race, ethnicity, age, and time with the organization, all intentionally selected by the embedded researcher as a means to capture a holistic overview of technology practice in a CBO.

While an ethnographic approach with a single organization would have itself provided important insights, we wanted to look outside DSNI to get a sense of broader applicability. Concurrent to our being embedded within DSNI, 14 interviews were conducted by another member of the research team with leaders in similar organizations throughout the country. This reach to these additional organizations gives us more confidence that the identified themes are not anomalous to a single organization. The interviews came from organizations primarily in the Northeast (10), with some from the Southwest (4). Two thirds of the interviewees were from small organizations ( $<15$ employees). These organizations were identified by the research team and contacted directly because they occupied similar goals and organizational mission, engagement approach, target communities and constituents, and publicly identifiable efforts to "modernize" for the digital age as our primary CBO, DSNI. Regardless of the organization's size, tech competency (determined by the researchers) varied considerably, and was not at all correlated to the size of the organization. ${ }^{2}$ The tech competency of DSNI, not represented in Table 1, is high. The same questions asked of DSNI were asked of the other organizations, save those specifically about the new tools implemented in DSNI. Interviews from these organizations are represented by the prefix

\footnotetext{
2 The measure of tech competency, which is represented in Table 1, was based on the assessment of the research team. When considering tech competency, the team looked at online presence (websites, social media), positions dedicated to technology and media (communications managers, social media organizers), publicly available technology focused grants or projects, the "newness" of public technology, among other things. The interview subjects were not asked to explicitly characterize their organization.
} 
Table 1. List of organizations and their characteristics.

\begin{tabular}{|c|c|c|c|c|c|c|}
\hline ID & Geography & $\begin{array}{l}\text { Staff/ } \\
\text { Size }\end{array}$ & $\begin{array}{l}\text { Target/ } \\
\text { Population/Served }\end{array}$ & Services/Provided & Focus & $\begin{array}{l}\text { Tech } \\
\text { Competency }\end{array}$ \\
\hline NB1 & Northeast & $<15$ & Brazilian-Immigrants & $\begin{array}{l}\text { Advocacy, } \\
\text { Job Training }\end{array}$ & $\begin{array}{l}\text { Immigration rights, } \\
\text { advocacy }\end{array}$ & Low \\
\hline NB2 & Northeast & $<15$ & $\begin{array}{l}\text { Specific } \\
\text { Neighborhood }\end{array}$ & Advocacy & $\begin{array}{l}\text { Community } \\
\text { Development, } \\
\text { Resilience }\end{array}$ & Medium \\
\hline NB3 & Northeast & $<15$ & $\begin{array}{l}\text { Specific } \\
\text { Neighborhood }\end{array}$ & Advocacy & $\begin{array}{l}\text { Health, } \\
\text { Sustainability }\end{array}$ & Low \\
\hline NB4 & Southwest & $<15$ & $\begin{array}{l}\text { Underserved } \\
\text { Populations }\end{array}$ & $\begin{array}{l}\text { Direct Services, } \\
\text { Advocacy }\end{array}$ & $\begin{array}{l}\text { Access to Food, } \\
\text { Advocacy }\end{array}$ & Medium \\
\hline NB5 & Northeast & $50-75$ & $\begin{array}{l}\text { Regional } \\
\text { Communities }\end{array}$ & $\begin{array}{l}\text { Advocacy, } \\
\text { Data Services }\end{array}$ & Urban Planning, & High \\
\hline NB6 & Northeast & $20-30$ & $\begin{array}{l}\text { Regional } \\
\text { Communities }\end{array}$ & $\begin{array}{l}\text { Advocacy, Data, } \\
\text { Network Infrastructure }\end{array}$ & Urban Planning & Medium \\
\hline NB7 & Southwest & $20-30$ & $\begin{array}{l}\text { Underserved } \\
\text { Populations }\end{array}$ & $\begin{array}{l}\text { Advocacy, Professional } \\
\text { Development; Network } \\
\text { Infrastructure }\end{array}$ & Healthcare & High \\
\hline NB8 & Northeast & $20-30$ & $\begin{array}{l}\text { Specific } \\
\text { Neighborhood }\end{array}$ & Advocacy and Policy & $\begin{array}{l}\text { Housing, Economic } \\
\text { Development }\end{array}$ & Low \\
\hline NB9 & Northeast & $<15$ & $\begin{array}{l}\text { Regional } \\
\text { Populations }\end{array}$ & Advocacy & Healthy Living & Medium \\
\hline NB10 & Southwest & $<15$ & Nationwide & $\begin{array}{l}\text { Community Planning, } \\
\text { Programming and } \\
\text { Resources }\end{array}$ & Urban Farming & High \\
\hline NB11 & Northeast & $<15$ & Youth & $\begin{array}{l}\text { Programming and } \\
\text { Advocacy }\end{array}$ & Youth Activism & Medium \\
\hline NB12 & Northeast & $<15$ & $\begin{array}{l}\text { Regional } \\
\text { Populations }\end{array}$ & $\begin{array}{l}\text { Network } \\
\text { Infrastructure }\end{array}$ & $\begin{array}{l}\text { Collaborative } \\
\text { Consumption }\end{array}$ & Low \\
\hline NB13 & Southwest & $<15$ & Women & $\begin{array}{l}\text { Programming and } \\
\text { Advocacy }\end{array}$ & Education & Medium \\
\hline NB14 & Northeast & $20-30$ & Youth & Programming & Arts and Technology & Medium \\
\hline
\end{tabular}

NB (not-Boston) in the citation. In total, we conducted, transcribed and analyzed 32 one-hour interviews.

Using a grounded theory approach (Glaser \& Strauss, 1967), coding of the interviews started during data collection, with codes being based on themes that emerged across the earliest interviews, and the codebook was iteratively developed throughout. Grounded theory allowed us to gather insights directly from a real-world, and lived experienced setting, without organizing our data collection around the resolution of specific hypotheses. As new codes were developed from fresh insights, they were applied to all the interviews using the qualitative analysis software Dedoose. To assure intercoder reliability, each interview was analyzed by at least two researchers and the codes were cross-referenced.

\section{Results}

We set out to answer two questions: 1) how do organizations innovate with technology while staying on mission? and 2) how do organizations stay relevant in a changing digital culture? Early in our analysis, themes began to repeat. The enthusiasm we had expected to unpack actually manifested as a series of tensions. Common to everyone we spoke to was a deep ambivalence, a sense that technology was both helping them do what they needed to do, and pulling them further and further away from those goals. Each of the tensions was articulated as contradiction and site of struggle (see Table 2). In this section, we briefly introduce the tensions and then elaborate based on the interview data. 
Table 2. Description of tensions.

Function vs. representation

Technologies in practice are always caught between function (or the immediate problems the technology is meant to solve and/or basic utility) and representation (or the meaning and symbolism that technology use generates both within and outside of the organization). This often manifests as a generalized anxiety among practitioners, especially when technology adoption is negotiated between the use and function of new technologies and the symbolism that those technologies bring to an existing organizational culture and context.

Amplification vs. transformation When communicating with constituents, many organizations default to a broadcast model of digital communication, where they use social media to broadcast an existing message out from a centralized position. This is opposed to a transformational model, where they engage in conversation with a broader public to alter an existing message, and meaning making is distributed horizontally. This is often the result of not understanding possibilities, and is most often seen as a point of tension.

Grassroots vs. grasstops An organization's feeling of authenticity is often captured in its technology use. Specifically, technology can sometimes be seen in opposition to the grassroots, which is very important to a certain generation of community based organizations. In many cases, an organization's use of technology was in direct dialogue with their identity as a "boots on the ground," "paper in hand" organization. This largely face-to-face model seemed to be challenged by the increased mediation possible with new ICTs, and this in turn led to unease/anxiety about a grassroots CBOs' identities.

Youth vs. adults

Even though the organizations we interviewed were not focused solely on youth work, they tended to think about their technology practices in generational terms. For most organizations, all new technologies were strongly associated with youth, even when they were not directed towards them, and youth were often considered tech savvy and thus valuable sources of tech-related knowledge.

\subsection{Function vs. Representation}

ICTs are adopted by organizations to solve real or perceived problems, ranging from the lack of efficiency of internal processes to insufficient community outreach and education (Gordon, Baldwin-Philippi, \& Balestra, 2013). The decision to adopt or create technologies is typically justified by their functional purposes ("we need to use social media to better reach youth"). But ICTs are burdened with meaning long before they are ever put to use ("social media represents innovation or progressive thinking") (Orlikowski, 2000; Sinclaire \& Vogus, 2011). One of the most important reasons why organizations adopt ICTs is the fulfillment of what the technology represents rather than the utility of what it accomplishes. In other words, when a community organization uses Facebook, they are seeking to get something done, but they are also seeking to represent that they can get things done. ICTs in CBOs are often used as an externalization of process; they are the purview of the communications specialist as much as they are the community organizer.

Consequently, when considering technology use in organizations, users bring existing meanings or perceptions of technology into their practices. The ways in which individuals and groups produce and share meanings of technology can be just as important as how they ultimately use them. The meanings people assign to ICTs structure their interactions with them-i.e., if Facebook is seen as a threat to one's job, one is likely to adopt it with caution and resentment. The sociologist Anthony Giddens' referred to this general process as structuration, wherein members of a social system produce and reproduce the systems in which they operate through acting within those systems (Giddens, 1986). The rules of any given bureaucracy are enacted, for example, they don't just come into being through written rules. Giddens' was interested in organizations and social life; he did not specifically refer to technologies, but this has been a logical domain for the application of his approach. Structuration theory has been adapted to this context within the tradition of adaptive structuration theory (AST), which asks how the rules (general logics) associated with particular technologies reinforce and are in tension with organizational rules and structures. DeScantis and Poole (DeSanctis \& Poole, 1994) define AST as a framework for studying variations in organizational change, specifically as it pertains to those moments of collision wherein the rules of a technology confront the rules of an organization.

The perceived benefit of a technology is often aligned with how others perceive its use, rather than what work it actually accomplishes. Using a mobile app to solicit feedback from constituents can provide useful data, but it can also make the organization appear innovative to the outside world. As people within organizations make 
decisions about adopting new technologies, there is a give and take between what work the tool actually does, and how people perceive organizations that use such tools. Indeed, sometimes representation can be paralyzing and/or significantly sacrifice the integrity of the functional adoption of tools.

As one leader of a youth organization put it: "I think it is a priority for everybody. If you're not being tech savvy nowadays, you're going to fall behind" (NB11). This sense of falling behind was a common theme among organizations, and typically was not associated with any one thing or tool, but a general unease with being perceived as a late adopter. Tech obsolescence was generally associated with organizational obsolescence. When it comes to technology, "we're just dreadful," according to a leader of a medium sized community based organization. "We could just coast for a period of time, but not forever. The organization is at risk if it doesn't find a way to put itself in a much more progressive, tech enabled...place" (NB6). This is not just a risk of being unresponsive to the communities it serves (a functional risk), but perhaps more importantly, not appealing to funders and boards (a representational risk). Of course there is some slippage here. Funders want evidence of function. They want to make data-informed decisions about what they support. But of course, funding priorities are often influenced by perceptions of progress, which tend to be correlated to new and emerging tools or technologies. This is certainly not always the case, but it was a frequently articulated sentiment from those working within $\mathrm{CBO}$.

The interview protocol we developed was focused on individual practitioners' relationship to the tools they use to do their work. We asked about how they make decisions about new technology, where they see themselves excelling in their work, and where they feel a sense of urgency. And, we asked them how they see the responsibility of their organization changing as work gets done through new tools and processes. The last question in the interview was meant to be playful and a bit provocative. We asked people to come up with a metaphor that describes their organization's use of technology. The question did not elicit feelings of enthusiasm that we assumed would characterize technology adoption; instead fear, confusion, and pointlessness were most commonly evoked. One person described their relationship to technology as "a deer in the headlights" (NB06). Another referred to technology as a "sourdough starter": "It's like you have to keep feeding it. You have to keep upgrading skills. You have to keep on top of technology and if you don't everything sort of dies or withers on the vine" (NB05). And another said, "technology is like a spiral staircase....It is constantly going to be running at this pace that you are not able to catch up with" (NB13).

The metaphor question provided some insight to the fact that people, regardless of the tech savviness of the organization, wanted to couch their perspective in a context of instability, disruption, and rapid change. They wanted to set the bar low so as to shield themselves from any potential expectations that the researcher brought to the conversation. As the research was presented to subjects as being about technology, most people felt the need to present themselves as non-experts and to present technology in general as an overdetermined category with specific meanings. Most were rather forthcoming with their feelings of anxiety, carefully framing other remarks in this context. This represents the instability that organizations feel in adopting new methods, especially when they feel those methods are thrust upon them by outside forces. "My observation is everything keeps changing all the time. It gets kind of frustrating after a while when everybody has moved on to the next thing and it's like, 'Wait, I didn't figure this one out yet'" (NB3). Adopting new tools to reach constituents was talked about as something people should be doing more of, if they only had the internal capacity to do so. Keeping up is an integral part of technology adoption; it is reflective of the availability of technical skills within organizations, but also the desire for relevance in an increasingly market-driven space of civic organizations.

The anxiety and promise of new tech tools presents a productive tension for most organizations. In fact, when we started this work, we assumed that the potentiality of tech would be the fundamental driver of adoption and use; but as it turned out potentiality and hopefulness were nearly always coupled with a sense of anxiety around keeping up and using tools well. This challenged our assumptions about the value of new tools and the capacity of organizations to use them. But the primary tension we identified was not within internal operations, but in the correspondence between the technology and the mission of the organization-especially when direct, face-to-face engagement characterizes the relationship with community constituents. How does technology connect to the grassroots? What are the gaps between online communication and face-to-face relationships? In the sections that follow, we explore this tension as it relates to the formation of organizational identities.

\subsection{Amplification vs. Transformation}

It's always more of that fear. 'Does this mean we're not going to do the face-to- face?' There was a lot of questions raised around who's going to use this technology, who's not, and so knowing that there's a part of our population that these tools are never going to work for, and how do we make sure that their voices are still heard in the process? I think that's the challenge, because it's not like we can do this and so we don't have to do face-to-face anymore. That will never be the case. I pray to God that will never be the case. (DSNI2-2)

The incorporation of new technologies into mission critical activities, such as communicating with constituents, is often met with resistance (Bimber, Stohl, \& Flanagin, 2009; Mercea, 2013). DSNI, for instance, understands itself as the facilitator of community relationships and as a 
vehicle for voice in the community (Medoff, 1999). But as they bring new technologies to bear on their work, they are forced to consider scenarios such as what happens when people are better able to self-organize online. Or, what happens when any individual with an Internet connection can forge direct communication lines to government? This leads to internal questioning as to the role of organizations whose missions are focused on connectivity, enhancing voice and building relationships. If people can connect on social media, then what's the value of the civic organization? The role of the organization-placebound, centralized, and bureaucratic-is positioned in opposition to the role of technology (Boulianne, 2009; Gordon et al., 2013; Shirky, 2008). As this spirit of technology is incorporated into the structural work of an organization, the representational tensions come into wide relief, and the desire to innovate is coupled with the implications of "disruption."

Civic organizations operate differently from industry or government agencies. While some, mainly formalized non-profits, do indeed have elements of top-down hierarchical structures, the organizations we examined in this study emphasize a horizontal and bottom-up approach for engaging with communities. For DSNI, their organizational structure is based on the idea that "the community," defined as residents of the neighborhood serving on the board and as consulted with surveys, decides the actions of the organization (Medoff, 1999). This distinction is important to note because ICTs are seen mainly as an expansion of organizational capacity rather than necessarily addressing the limitations of organizational structures.

But mission-driven organizations are seeking a competitive edge, not necessarily from competing organizations wanting to serve the same population, but from technologies themselves. Organizations charged with representing geographically-located communities need to contend with their relevance in the wake of networked tools that profess to enable communities to represent themselves. Many of the organizations we spoke to formed in a pre-internet context where facilitation of community dialogue and networking was core to their missions. ICTs are forcing a shift where these organizations are confronted with having to cede some control of facilitation to third party technologies. According to one organization: "We're working to have [our social media] designed so that it is largely maintained by community members and we just curate it" (NB10).

The notion of the organization as curator of a community conversation is consistent with how many organizations already see themselves in a pre-internet context. ICTs, then, are used strategically to maintain an existing narrative of grassroots organizing. In analyzing the data, we coded for the communication strategies adopted to construct that narrative. Notably, we identified a difference between the strategies of amplification and transformation. Amplification is the use of ICTs to amplify an existing message generated by the organiza- tion, whereas transformation is the use of ICTs to transform messages through dialogue, co-creation, etc. Our interest is not in assigning value to one mode over the other, but simply to understand the intentionality behind ICT use. Most of the time, amplification was the stated goal. People sought to use ICTs to extend a message or bring attention to the organization, in the tradition of broadcast media. In some cases, this plays out along the lines of experience with technology, where less tech-savvy organizations adopt more of a broadcast model and more tech-savvy organizations tend to think about participation in networks. Some of this is due to the capacity of organizations-small organizations with a single IT person or small or non-existent communications teams, are inevitably going to be more conservative in their approach. However, most of the time, organizations demonstrated a diversity of intentions, sometimes in conflict with one another. The person in charge of communications might be focused on generating conversation, whereas the community organizer might be most interested in getting people to show up to events. For example, people at DSNI expressed a range of sentiments about the possibility space of ICTs, from a means of solidifying the organization's role in the community, to a safeguarding of transparent interactions. According to one person from the organization: "I think the goal of technology and social media would be to transmit important knowledge to the household and to the parents" (DSNI12). Or, another person suggested that the value of using "new tools...is to try and get more information out to folks in the neighborhood" (DSNI13). But within the same organization, yet another person spoke of technology's ability "to give residents a stronger voice in community planning processes" (DSNI4).

Amplification strategies reinforce the centrality of the organization within the community. They implicitly position the organization in the role of meaning-maker, with the technology aiding in that role, but not necessarily challenging it. This appropriation is a common strategy for taming unknown behaviors of new technologies, by remediating old technologies through new ones (Bolter \& Grusin, 1996). The organization can point to the fact that it uses Facebook, even while not embracing the networked affordances of the tool. Transformative strategies (i.e., increasing voice), on the other hand, represent a greater openness to the organization as facilitator of meaning, not meaning-maker:

We are trying to figure out how we can use the technology to enhance some of the work that we do.... think we could really use those [technologies], not only to get the word out about the organization and people to join, but for people to really meet each other and make connections and get to know each other. (NB14)

Another organization put it this way: "I think technology really gives you a mechanism for implementing in a way 
that I don't know how it could be done without technology" (NB3). It is particularly important to recognize that this diversity exists within single organizations. DSNI on the one hand wholly embraces technology and seeks to find transformative uses for it, while on the other hand, it is deeply suspicious of technology encroaching on the authenticity of the grassroots.

\subsection{Grassroots vs. Grasstops}

Many of the organizations we interviewed use grassroots organizing techniques to build their constituency. In recent years, both scholars and practitioners have examined the changing role of community organizing in light of ICTs (Bennett \& Segerberg, 2012; CostanzaChock, 2014; Minch, 2005; Stoecker, 2002). Among Social Movement Organizations (SMOs), the rise of "online organizers" represents efforts to reconceptualize community organizing for use with the Internet (Freelon, 2014; Harlow, 1996; Kahn \& Kellner, 2004). Key questions to consider in this regard are: What happens to community organizing, whose strengths are tied to person-to-person engagement, when it becomes mediated? Are the affordances of new technologies interpreted through grassroots community organizing?

The concept of the grassroots, and all that it implies, featured very prominently in our interviews. Several of the interviewees mentioned specific training in community organizing, and several were staffed their organizations as community organizers. As someone from DSNI put it: "I think that I would still say we are more, by and large, more of a face-to-face, less technology based type organization" (DSNI2). Face-to-face was characterized as more than just a strategy; it was an identity to which people connect, representing authenticity that is being challenged by overreliance on technology. The logic of grassroots organizing is an important structural framework within which many organizations operate. With the growth of civic technologies to improve the efficiency of governments and to facilitate community engagement in political process, it's easy to forget (or overlook) that grassroots community organizing was an early "innovation" employed by organizations to overcome systemic participation barriers. This was the case for DSNI, which emerged as a response to the perceived dehumanization and bureaucratization of traditional local government processes. The romanticized town hall-model of deliberative micro-politics was systematically out of reach of the constituents that DSNI came to serve, and community organizing became a means to engage and empower people (Medoff, 1999).

It is in this context that the Alinsky model of community organizing has become a popular strategy over the years, which implies building relationships one person at a time, rather than being reduced to data in the fashion of hyper-rational bureaucracies (Miller, 2009). The Alinsky model of organizing, for example, has very concrete structural outcomes: to engage the unengaged with person-to-person methods, such as door-knocking, flyering, and home visits-in short, emphasis is placed on political participation in the terms and spaces of common people that are systemically and culturally excluded from formal politics. As such, the Alinsky model has gained popularity for engaging communities that fall through the cracks of formal electoral and deliberative politics, such as low-income people, immigrants, and communities of color (Ganz, 2002; Medoff, 1999). The grassroots has representational value-for the people with whom we spoke, the grassroots represented authentic relationships with constituents, even if it didn't always create them.

In this sense, the grassroots has traditionally represented the antithesis of state politics, largely because governments cannot easily replicate it as it is difficult to scale and relies heavily on unpaid work. At the same time, there are numerous examples that show the blurring of CBOs and government in this regard (Kreiss, 2012; Stein, 1986). But, in many civic organizations, the tension is not only between the small organization and the government or corporation, but between the small organization and social media technologies. Especially as technologies aid the professionalization and commodification of the grassroots (sometimes referred to as "astroturfing"), organizations are more actively policing the lines between authentic and inauthentic community engagement (Walker, 2014). For organizations framing their intervention with grassroots organizing methods, such as DSNI in our case, civic tech holds promise for their work, but not outside of real fears that technology may reproduce the alienation and bureaucratization that led to the rise of community organizing in the first place.

While civic tech in government is often characterized through the lens of new practice and liberation from constrained bureaucracies, the way these same technologies play out within civic organizations is importantly distinct; in fact, they are in opposition to the technological efficiency espoused by most government tech projects (Gordon \& Walter, 2016). Structuration takes place between the logics of the organization and the ICT; but additionally, the logic of grassroots organizing, as a horizontal model for facilitating political participation and community empowerment, impacts how technologies are considered, adopted and implemented.

Examples of this include the metaphors of paper, doors and boots. According to an organizer at DSNI: "We use A LOT of paper, like one-on-one communication that happens when you're flyering, so we use a lot of the flyers when we door knock" (DSNI8). When asked specifically about social media approaches to organizing, another person acknowledged the importance of digital tools but then quickly reverted to the primacy of paper: "A lot of it is also creating flyers and going door to door, I do a lot of door work....I'm boots on the ground, it's kind of my style of organizing.... drop off flyers in peoples' mailboxes and let them know about upcoming community meetings (DSNI7). The grassroots is a structure 
of meaning that organizers bring to any decision about applying ICTs to their work and conversely, they apply the representation of ICTs to their "traditional" organizing practices, often as a way of justifying the intensity and intimacy of the approach. For example, in defending the face-to-face, one DSNI organizer said: "[Online] I think people can tend to be less focused, if they are somewhere else and there is a lot that is going on, as opposed to like, being in a room and having to work on something all together" (DSNI8). And another summed it up this way: "In general [we focus on] keeping it to the traditional, like, grassroots organizing tools of going out and having one-on-one conversations" (DSNI7).

As a strategy, there is nothing surprising about organizations using techniques of door-knocking and flyering. What is surprising is the extent to which organizations use physical metaphors to constitute their identities. The theme of handing people flyers or postcards and transforming that moment of information exchange into a moment of human connection, was rather prominent and defined in opposition to texting or social media exchanges, wherein the scale might be larger, but the intimacy lost. "The biggest danger and challenge is that we don't have face-to-face conversations with people" (DSNI2). With DSNI in particular, an organization with decades of history with the community it serves, technology is certainly embraced, but only as an addition to paper:

Technology is not an end in itself. It's a great tool. It's not a substitute for old-fashioned community organizing. You can't just say well, I emailed a thousand people and I don't know why they didn't come to the meeting. You've got to still do the work but I think in terms of more of an interactive two-way tool it opened a lot of eyes about how we could engage residents in meaningful conversations. (DSNI4)

Most community organizations continue to define themselves through paper-based relationships (Ohmer \& Beck, 2006; Speer \& Han, 2018), and technology is carefully characterized in dialogue with that authenticity.

"It's a huge concern of anybody who does community organizing," said a staff member at DSNI, "will we get everybody's input via technology, and who does that leave out" (DSNI2). But in addition to fears of missing individuals, ICTs are generally perceived as compromising the integrity of relationships between individuals: "Through the computer you don't have that person to person trust and bonding that can develop when you're building relationships or that need to develop as you're building...There's not that personal connection." (DSNI8)

\subsection{Youth vs. Adults}

The structuration of technologically mediated grassroots plays out along generational lines. The efficacy of civic tech is most often connected to youth, both in terms of functional strategies of reaching a youth population, and also in terms of representational strategies of appearing to appeal to youth. In every single one of our interviews, ICTs were at some point connected to the habits of young people. Most organizations have done informal surveys or observations to better understand the behaviors of young people in their communities. According to a youth organizer at DSNI:

Talking from a youth perspective, the young people are definitely..."text me. Don't call me. I'm not going to answer my phone. Send me an email. Maybe I'll look at it"....Then there's a whole other group of young people who didn't even know how to address envelopes, because it's not at all in the realm of what they do. They're, "Just send me an email", and we're, "We're just trying to send you a care package, and goodies, and...." We find, now, that's much more of the way that they respond to us, and "do a doodle, and don't send me a bunch of dates, just let me click what I want, and see what everybody else said, and go about my merry way." (DSNI2)

There is an understanding of how youth communicate and there is a recognition that the organization needs to respond to those communication patterns. DSNI is very good at tapping into the tech savvy of youthunderstanding that youth tend to have large online social networks and can help with getting the word out about events and projects:

The youth help us, from time to time, so we have played around with whether to do a Vine, all of those different things, because they're just using them, and so in the course of having them help us to organize, we're asking them, "How do you get the word out about something?" They're utilizing these tools, and we're not, so that's definitely some of where we get our ideas. (DSNI2)

However, as discussed above, these strategies are in direct opposition to paper-based authenticity, which remains an important representation of the organization. Often what happens is that youth communication is seen as a process that is carefully distinguished from the organization's identity. In other words, tech-enabled youth relationships are seen as aiding in engaging adults, in service to the structural value of authentic relationships, but not as ends in themselves. Someone from DSNI expressed this tension through a desire to see youth, adults, technology, and paper clearly integrated:

Maybe we could integrate technology and door knocking. The youth, when they went out to get feedback from parents about education, they brought their iPads. They had the parents filling out a survey while they were talking to them, so that was cool, they could just ask them questions and then they would plug it 
into their iPads and in the end they had graphs and stuff that summarized the feedback. (DSNI8)

In this example, technology-equipped youth are a vehicle to engage non-technology equipped adults. It accomplishes a very specific task of gathering information (which of course could have been done on paper), but also embodies a forward-thinking approach through the representation of the iPad. This example points to a strategy that seeks not to compromise the authenticity of paper, while at the same time producing a powerful symbol (young person canvassing with iPad) for the organization.

In general, organizations are not seeking new practice through ICTs, but instead seeking to complement existing practice with civic tech tools. This is not surprising, since technological change often does not occur as disruptively as commonly represented. But what was surprising in our research was the consistency in which organizations cycled through a process of considering and adopting ICTs. After the representational tensions surrounding the grassroots and the digital were reconciled, only then did the discourse move to understanding the functional potential of the tool. The iPad example is illustrative of this sequencing, notoriously adopted by organizations (especially in the education sector) because of what it represents rather than what it does (deAbreu, 2015). Organizations sometimes claim to be innovative simply because they purchased 50 iPads. The technology itself becomes a means of capturing youth-"youth will take us more seriously if we give them iPads"-and in turn, youth come to represent authenticity-"if youth are engaged, then we are "keeping it real.'" This circular reasoning has become quite prevalent in organizational culture, and it is important that effort is made in disentangling representation from the thing it represents.

\section{Conclusions}

The four tensions described in this study are overlapping and in some cases contradictory. When it comes to the grassroots, technology can be seen as inauthentic. But, as a means of capturing youth in a process, technology can facilitate the appearance of authenticity. This research has highlighted the complexity of the integration of technologies into the work of CBOs, specifically the challenges associated with humans delegating their "public work" to non-human actors. The issues go well beyond an organization's capacity to access and support technology; CBO staff are daily confronting the meanings associated with technologies as they make decisions to adopt and integrate them into organizational practice. The functional concerns of civic technologies (the way in which they address problems such as lack of efficiency) need to be understood in combination with the representational concerns (the way in which they represent change, innovation, inauthenticity and youth). As organizations struggle to fulfill their missions, they are confronted with the pressures of all that technology repre- sents. These pressures are sometimes aligned with missions (youth and innovation, for example), and sometimes directly pushing up against hard fought grassroots identities. They provide a lens through which to see the field of civic tech, where the logics of grassroots organizing push up against the logics of tech-centered innovation and scalability. The tensions between face-to-face and mediated practices are richly textured and should not be seen as a simple binary or mistaken for technophobia or resistance to change. Community organizing is a structured system within which many civic organizations operate, and the invention, adoption and deployment of civic tech, exists within that context.

Our research points to a need to consider the practices of technology use and not just the outcomes of technologies. There is considerable unevenness in the types of organizations using civic tech, which has impact not only on the practicalities of implementation, but as we have demonstrated, in the values assigned to the work that tools do. It is important to understand the distinction between function and representation and then understand how each is put into practice. Our research has looked specifically at the challenges practitioners face when delegating tasks to non-human actors and the associated meanings that come along with that delegation. We have provided insight into this process by focusing on four tensions that are top of mind as practitioners incorporate technology into their public work. These include: function vs. representation, amplification vs. transformation, grassroots vs. grasstops, and youth vs. adults.

There were, however, limitations to this study. First, we focused only on US-based organizations. There is no doubt that if we were to look at other national contexts our findings would be different. However, we hope that this article can provide a productive foundation for future research. Additionally, we spent considerable time embedded within a single US organization. Our interactions with the other 14 organizations was minimal. We conducted interviews with various organizational leaders, but didn't have the opportunity to embed within them, therefore our insights into these organizations are limited to what people reported. Our initial insights were gained primarily through an ethnography with a single organization, and then verified through our conversations with a range of other organizations. Ideally, we could have expanded our ethnographic methods to other organizations, but we lacked the resources to do so. With that said, we have confidence that our findings can productively contribute to future research.

Considering the complexity of technology adoption, including the internal and external demands on practitioners to adopt new tools and processes, can provide context for future work that looks at the effectiveness of such tools and processes. Future work in the area of civic tech, specifically as it pertains to $\mathrm{CBO}$, should consider the complexity of implementation and adoption as it seeks to evaluate impact. 


\section{Acknowledgments}

We would like to thank the John S. and James L. Knight Foundation for their generous support of this research.

\section{Conflict of Interests}

The authors declare no conflict of interests.

\section{References}

Bennett, W. L., \& Segerberg, A. (2012). The logic of connective action. Information, Communication, \& Society, 15(5), 37-41.

Bimber, B., Stohl, C., \& Flanagin, A. (2009). Technological change and the shifting nature of political organization. In A. H. Chadwick (Ed.), Routledge handbook of internet politics. New York, NY: Routledge.

Bolter, J. D., \& Grusin, R. (1996). Remediation. Configurations, 4(3), 311-358.

Boulianne, S. (2009). Does internet use affect engagement? A meta-analysis of research. Political Communication, 26(2), 193-211. http://doi.org/10.1080/ 10584600902854363

Bowles, J., \& Giles, D. (2012). New tech city report. New York. NY. Retrieved from http://nycfuture.org/ research/publications/new-tech-city

Boyte, H. (2019). A new civic covenant. Twin Cities Pioneer Press. Retrieved from https://www.twincities. com/2019/01/20/harry-c-boyte-a-new-civic-covenant

Costanza-Chock, S. (2014). Out of the shadows, into the streets! Cambridge, MA: MIT Press.

Couldry, N. (2012). Media, society, world: Social theory and digital media practice. Cambridge: Polity.

deAbreu, B. (2015). iPads in school. Engagement Lab at Emerson College. Retrieved from http:// civicmediaproject.org

DeSanctis, G., \& Poole, M. S. (1994). Capturing the complexity in advanced technology use: Adaptive structuration theory. Organization Science, 5(2), 121-147.

Freelon, D. (2014). Online civic activism: Where does it fit? Policy \& Internet, 6(2), 192-198.

Ganz, M. (2002). What is organizing? Social Policy, 33(1), 16-18.

Garud, R., Hardy, C., \& Maguire, S. (2007). Institutional entrepreneurship as embedded agency: An introduction to the special issue. Organization Studies, 28(7), 957-969. https://doi.org/10.1177/ 0170840607078958

Giddens, A. (1986). The constitution of society. Berkeley, CA: University of California Press.

Glaser, B., \& Strauss, A. (1967). The discovery of grounded theory: Strategies for qualitative research. Chicago, IL: Aldine Pub Co.

Goldstein, B. (2013). Open data in Chicago: Game on. In B. Goldstein \& L. Dyson (Eds.), Beyond transparency: Open data and the future of civic innovation. San Francisco, CA: Code for America Press.
Gordon, E., Baldwin-Philippi, J., \& Balestra, M. (2013). Why we engage: How theories of human behavior contribute to our understanding of civic engagement in a digital era (Berkman Center Research Publication No. 21). http://doi.org/10.2139/ssrn.2343762

Gordon, E., \& Mihailidis, P. (Eds.). (2016). Civic media: Technology, design, practice. Cambridge, MA: MIT Press.

Gordon, E., \& Mugar, G. (2018). Civic media practice: Identification and evaluation of media and technology that facilitates democratic process. Boston, MA. Retrieved from https://elabhome.blob.core. windows.net/resources/civic_media_practice.pdf

Gordon, E., \& Walter, S. (2016). Meaningful inefficiencies: Resisting the logic of technological efficiency in the design of civic tech. In E. Gordon \& P. Mihailidis (Eds.), Civic media: Technology, design, practice. Cambridge, MA: MIT Press.

Harlow, R. E. (1996). Still participating after all these years: A study of life task participation in later life. Personality Processes and Individual Differences, 71(6), 1235-1249.

Heuer, L., Penrod, S., \& Kattan, A. (2007). The role of societal benefits and fairness concerns among decision makers and decision recipients. Law and Human Behavior, 31(6), 573-610. http://doi.org/10.1007/ s10979-006-9084-2

Jacob, N. (2015). Guide for embedding breakthrough innovation in local government. New York, NY. Retrieved from https://www.livingcities.org/resources/ 286-city-accelerator-guide-for-embeddinginnovation-in-local-government

Kahn, R., \& Kellner, D. (2004). New media and internet activism: From the "Battle of Seattle" to blogging. New Media and Society, 6(1), 87-95.

Kreiss, D. (2012). Acting in the public sphere: The 2008 Obama campaign's strategic use of new media to shape narratives of the presidential race. Media, Movements, and Political Change: Research in Social Movements, Conflicts and Change, 33, 195-223.

Latour, B. (1990). On actor-network theory: A few clarifications plus more than a few complications. Philosophia, 25(3), 47-64.

Maguire, S., Hardy, C., \& Lawrence, T. B. (2004). Institutional entrepreneurship in emerging fields: HIV/AIDS treatment advocacy in Canada. Academy of Management Journal, 47, 657-679.

Medoff, P. (1999). Streets of hope: The fall and rise of an urban neighborhood. Boston, MA: South End Press.

Mercea, D. (2013). Probing the implications of Facebook use for the organizational form of social movement organizations. Information Communication and Society, 16(8), 1306-1327.

Miller, M. (2009). Alinsky for the left: The politics of community organizing. Dissent, 57(1), 43-49. http://doi. org/10.1353/dss.0.0106

Minch, H. (2005). Considerations at the intersection: Community organizing and strategic communica- 
tions. Social Policy, Summer, 72-76.

Nabatchi, T., \& Leighninger, M. (2015). Public participation for the 21st century. New York, NY: Jossey-Bass.

Noveck, B. S. (2008). Wiki-government: How opensource technology can make government decisionmaking more expert and more democratic. Democracy: A Journal of Ideas, 7. Retrieved from https:// democracyjournal.org/magazine/7/wiki-government

O'Brien, D. (2018). The urban commons: How data and technology can rebuild our communities. Cambridge, MA: Harvard University Press.

O'Reilly, T. (2010). Government as platform. In D. Lathrop \& L. Ruma (Eds.), Open government: Collaboration, transparency, and participation in practice (pp. 12-39). Sebastopol, CA: O’Reilly.

Ohmer, M., \& Beck, E. (2006). Citizen participation in neighborhood organizations in poor communities and its relationship to neighborhood and organizational collective efficacy. Journal of Sociology \& Social Welfare. Detroit, MI: Thomson Gale. Retrieved from http://heinonlinebackup.com/hol-cgi-bin/get_ pdf.cgi?handle=hein.journals/jrlsasw33ion $=13$

Open Plans. (2012). Field scan of civic technology. New York, NY: Open Plans.

Orlikowski, W. J. (2000). Using technology and constituting structures: A practice lens for studying technology in organizations. Organization Science, 11(4), 404-428.

Patel, M., Sotsky, J., Gourley, S., \& Houghton, D. (2013). The emergence of civic tech: Investments in a growing field. Miami, FL: John S. and James L. Knight Foundation.

Place Matters, \& Ford Foundation. (2014). Engagement technology for all. New York, NY: Place Matters and Ford Foundation. Retrieved from http:// placematters.org/blog/wp-content/uploads/2014/
03/PlaceMatters_EngagementTechForAll_Final_ 20140310.pdf

Poje, J. (2011). Gov 2.0: Interaction, innovation and collaboration (cover story). Public Lawyer, 19(1), 2-11.

Schrock, A. R. (2018). Civic tech: Making technology work for people. Los Angeles, CA: Rogue Academic Press.

Shirky, C. (2008). Here comes everybody: The power of organizing without organizations. New York, NY: Penguin Press.

Simon, J., Bass, T., Boelman, V., \& Mulgan, G. (2017). Digital democracy: The tools transforming political engagement. London: Nesta. Retrieved from http:// www.nesta.org.uk/publications/digital-democracytools-transforming-political-engagement

Sinclaire, J. K., \& Vogus, C. E. (2011). Adoption of social networking sites: An exploratory adaptive structuration perspective for global organizations. Information Technology and Management, 12(4), 293-314. http://doi.org/10.1007/s10799-011-0086-5

Speer, P., \& Han, H. (2018). Re-engaging social relationships and collective dimensions of organizing to revive democratic practice. Journal of Social and Political Psychology, 6(2), 745-758.

Stein, B. A. (1986). Between organization and movement: ACORN and the Alinsky method of community organizing. Berkeley Journal of Sociology, 31, 93-115.

Stoecker, R. (2002). Cyberspace vs face to face community organizing in the new millennium. Perspectives on Global Development and Technology, 1(2), 143-164.

Walker, E. (2014). Grassroots for hire: Public affairs consultants in American democracy. Cambridge: Cambridge University Press.

Wells, C. (2015). The civic organization and the digital citizen: Communicating engagement in the networked age. New York: NY: Oxford University Press.

\section{About the Authors}

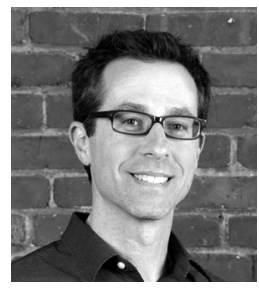

Eric Gordon is Professor of Civic Design and the Director of the Engagement Lab at Emerson College in Boston. His research focuses on the transformation of public life and governance in digital culture, and the incorporation of play into collaborative design processes. He is the editor of Civic Media: Technology, Design, Practice (MIT Press, 2016) and the author of Meaningful Inefficiencies: Transforming Civic Life Through Play and Care (Oxford University Press, 2020).

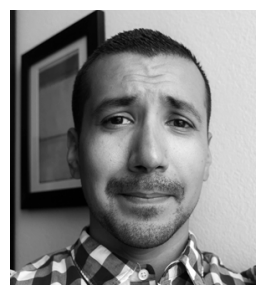

Rogelio Alejandro Lopez is Doctoral Candidate in Communication at the Annenberg School for Communication and Journalism at the University of Southern California, where his work centers on social movements, civic media, and youth culture. His dissertation is a comparative look into the role of media strategies and cultural production in developing a "civic imagination" among contemporary youth social movements. 